\title{
El Gabal en Roma. Convulsión social e inestabilidad política
}

\author{
El Gabal in Rome. Social Convulsion and Political Inestability
}

\author{
JOSÉ IGNACIO SÁNCHEZ SÁNCHEZ \\ Universidad Nacional de Educación a Distancia \\ w1900w@gmail.com
}

Resumen: El presente artículo estudia las repercusiones políticas y sociales motivadas por la introducción del culto del dios solar sirio El Gabal en la ciudad de Roma, por parte del emperador Heliogábalo (218-222). La ubicación de la deidad en la cúspide del panteón religioso, así como el resto de innovaciones acometidas en materia religiosa, fueron cuestiones sumamente controvertidas y se apuntan como una de las causas de la sustitución del emperador por su primo, Alejandro Severo. En las siguientes páginas se ofrece una aproximación a la realidad religiosa del momento, así como un análisis de las reacciones de los diversos sectores de la sociedad ante estas medidas, con la intención de aclarar el impacto que pudieran ocasionar entre el pueblo romano.

Palabras clave: Religión romana, El Gabal, Heliogábalo, siglo III, henoteísmo.

Abstract: The present paper studies the social and political consequences triggered by the cult of the Syrian sun god El Gabal in the city of Rome, by the Emperor Elagabalus (218-222). The deity's location on the cusp of the religious pantheon, as well as the rest of religious innovations undertaken, were highly controversial issues and are pointed out as one of the causes of the replacement of the emperor by his cousin, Alexander Severus. The following pages offer an approach to the religious reality of that moment, as well as an analysis of the response to these measure of different sectors of the society, with the intention of clarifying the impact that could cause among the Roman people.

Keywords: Roman religion, El Gabal, Elagabalus, $3^{\text {rd }}$ century, Henoteism.

Recibido: 3 de junio de 2017; aceptado: 22 de noviembre de 2017; publicado: 27 de marzo de 2018. Revista Historia Autónoma, 12 (2018), pp. 43-60. e-ISSN: 2254-8726; DOI: https://doi.org/10.15366/rha2018.12.002. 
Introducción

A la luz de lo que refieren las fuentes textuales sabemos que la aclamación de Heliogábalo fue orquestada por su entorno. Las riquezas de su abuela Julia Mesa, el falso rumor de que el muchacho era hijo ilegítimo de Caracalla ${ }^{1}$ y el descontento por parte de determinados sectores con el gobierno de Macrino posibilitaron que el ejército primero y después el Senado aceptasen al nuevo emperador. Pronto quedó claro, en cualquier caso, que estos apoyos e intentos de legitimación no iban a ser suficientes. Los pilares sobre los que se asentó el poder del sirio fueron precarios desde el principio: un joven de apenas catorce años, oriental, proveniente de una familia influyente pero alejada del poder necesitaba apuntalar su autoridad con rapidez y de forma contundente. Las actitudes de Heliogábalo en lo referido a su conducta pública y sexual, su desinterés hacia las tareas de gobierno y sus innovaciones en materia religiosa acabaron por conformar un frente opositor cada vez más amplio.

El presente trabajo se centra en el análisis de la inestabilidad política y el impacto social motivados por las controvertidas medidas religiosas llevadas a cabo por Marco Aurelio Antonino Augusto (ca. 202-222) conocido como Heliogábalo, entre las que la promoción de El Gabal — deidad principal de su Emesa natal— hasta lo más alto del panteón fue la más importante y sin duda hubo de ser tremendamente polémica, pero no fue la única.

\footnotetext{
${ }^{1}$ Sobre la aclamación, las fuentes - Ab excessu divi Marci libri octo y la Historia Romana - nos brindan dos versiones no contradictorias pero si distintas. Para Herodiano, Heliogábalo subió al poder porque la ambición de Mesa por recuperar la notoriedad perdida desde que fue expulsada de Roma por Macrino fue la fuerza que lo elevó. Urdió en connivencia con su familia y sus adláteres una compleja estrategia para entronizar al mayor de sus nietos. Supo manejar emocional y económicamente a la Legio III Gallica para que aclamase al joven. En Dion Casio, Gannys - un personaje que no es nombrado en ninguna otra fuente - es el principal instigador de la revuelta. Tras la muerte del padre natural del niño hubo de convertirse en una suerte de tutor/protector para este. Fue Gannys quien hizo correr el rumor de su supuesta filiación con Caracalla y quien convenció a los soldados para levantarse en armas contra Macrino. Se ha señalado la dependencia entre estas dos fuentes en la narración de la vida y el gobierno de Heliogábalo. Vid. Scheithauer, Andrea, "Die Regierungszeit des Kaisers Elagabal in der Darstellung von Cassius Dio und Herodian", en Hermes, vol. 118, 3 (1990), pp. 335-356. Se debe llamar la atención también sobre la parcialidad de la tercera fuente de la que bebe principalmente este estudio, la Hist. Aug. Es de sobra conocida su falta de rigor y ha de recordarse la caracterización como un "mal emperador" de Heliogábalo — así como el retrato por oposición de su primo Alejandro Severo- para evitar caer en interpretaciones erróneas o inexactas. Vid. Rodríguez Gervás, Manuel José, "La vida de los emperadores infames Cómodo y Heliogábalo: a propósito de la Historia Augusta", en Alvar Ezquerra, Jaime et al. (eds.), Sexo, muerte y religión en el mundo clásico, Madrid, Ediciones Clásicas, 1994, pp. 193-203; Icks, Martjin, "Heliogabalus, a Monster on the Roman Throne: The Literary Construction of a «Bad» Emperor", en Rosen, Ralph M. e Ineke Sluiter (eds.) KAKOS, Badness and Anti-Value in Classical Antiquity, Leiden, Brill, 2008, pp. 477-488. DOI: https://doi.org/10.1163/ ej.9789004166240.i-516.139, donde se analizan los loci communes empleados en la caracterización de los "buenos/ malos emperadores". Se ha propuesto una división en dos partes de la Vita Heliogabali: desde 1,4 hasta 18,3 se considera una biografía relativamente fiable, pero desde este punto hasta el pasaje 33,8 se ha calificado como pura ficción. Mader, Gottfried, "History as Carnival, or Method and Madness in the Vita Heliogabali", en Classical Antiquity, vol. 24, 1 (2005), pp. 131-172. DOI: https://doi.org/10.1525/ca.2005.24.1.131. También, algunos autores proponen la sugerente teoría de que este relato no es sino un velado retrato de la biografía de Constantino, en tono satírico y malicioso. Es esta cuestión de enorme interés y merecedora de un estudio. $C f$. Turcan, Robert, "Héliogabale précurseur de Constantin?", en Bulletin de l'Association Guillaume Budé, 47 (1988), pp. 38-52. DOI: https://doi.org/10.3406/bude.1988.1349; y Cracco Ruggini, Leilla, "Elagabalo, Costantino ei culti siriaci nella Historia Augusta", en Historiae Augustae Colloquium Parisinum, París, De Boccard, 1991, pp. 123-146.
} 
Sobre la pertinencia de este trabajo se debe señalar que, aunque existen varias investigaciones centradas en la figura del emperador ${ }^{2}$ y algunas que concretan en el estudio del culto a $E l \mathrm{Gabal}^{3}$, se echa de menos un estudio que ponga el foco en las reacciones que se dieron en los diversos estratos de la sociedad romana ante la introducción del culto. El trabajo se restringe en términos de cronología al reinado de Heliogábalo (218-222) y la capital del Imperio es el espacio en el que esencialmente se ha centrado el análisis.

\section{Antecedentes: la política religiosa de los Severi}

Bajo los Severos, el panorama religioso fue dinámico y diverso. Comentemos algunas de las principales tendencias que se pueden observar. Por una parte, y con la idea de alimentar la ilusión de continuidad dinástica diseñada por Septimio Severo ${ }^{4}$, se trató de mostrar una sincera adhesión al panteón tradicional romano. Al mismo tiempo y sin que supusiera una contradicción a lo anteriormente mencionado, sabemos que se aceptaron sin mayor problema deidades ajenas a la raigambre ideológica y espiritual más tradicional, siempre que estos cultos no resultasen políticamente peligrosos o disonantes desde la perspectiva social. Heliogábalo rompió con ambas concepciones ideológicas: la inserción del culto de El Gabal en Roma es un acto que se halla en las antípodas del respeto a la tradición, al tiempo que supuso un gran choque cultural y una distorsión considerable en el fluir de las relaciones del emperador con importantes sectores de la sociedad.

La Constitutio Antoniniana reconoció, además de la ciudadanía de los hombres libres, su facultad para vincularse al culto local o de su lugar de procedencia. El edicto de Caracalla respaldó legalmente una realidad que ya era innegable: un Imperio diverso en cuanto a lo étnico

\footnotetext{
${ }^{2}$ Desde clásicos como como Butler, Orma Fitch, Studies in the Life of Heliogabalus, Nueva York, McMillan \& Co, 1908; Villeneuve, Roland, Héliogabale: le César fou, París, Pierre Amiot, 1957; o Hay, John Stuart, The Amazing Emperor Heliogabalus, Londres, McMillan \& Co, 1911; hasta estudios modernos como Icks, Martjin, The Crimes of Elagabalus, Nueva York, IB Tauris, 2011; Arrizabalaga y Prado, Leonardo, The Emperor Elagabalus: Fact or Fiction? Cambridge, Cambridge University Press, 2010; o Gualerzi, Saverio, Né uomo, né donna, né dio, né dea: ruolo sessuale e ruolo religioso dell'imperatore Elagabalo, Bolonia, Pàtron, 2005.

${ }^{3}$ Optendrenk, Theo, Die Religionspolitik des Kaisers Elagabal im Spiegel der Historia Augusta, Bonn, Rudolf Habelt, 1968; Halsberghe, Gaston H., The Cult of Sol Invictus, Leiden, Brill Archive, 1972; o Badaracco, Edgardo, Il Culto del Deus Elagabalus dal I al III secolo d. C. attraverso le testimonianze epigrafiche, letterarie e numismatiche, tesis doctoral, Università degli Studi di Sassari, 2017; más reciente aún, Sánchez Sánchez, José Ignacio, La introducción del culto de El Gabal en Roma, Madrid-Salamanca, Signifer, 2017.

${ }^{4}$ Kemezis, Adam M., Greek narratives of the Roman Empire under the Severans. Cassius Dio, Philostratus $y$ Herodian, Cambridge, Cambridge University Press, 2014, p. 74. DOI: https://doi.org/10.1017/CBO9781107477308 Entre otras medidas, Septimio Severo otorgó a su hijo el nombre de Antonino. Heliogábalo también tomó esta denominación como sabemos a través de las fuentes. Particularmente interesantes son las contradictorias alusiones en la Hist. Aug., que aparecen tanto en su vita como en la de Alejandro Severo. Si en Hist. Aug. Heliog., 18,1 o 34,6 se le considera el último de los Antoninos, otros pasajes como Hist. Aug. Alex. Sev., 1, 1-2 o 2,2 refieren que no merecía tal título al no tener ninguna de las cualidades de la citada estirpe imperial. Vid. Scholtemeijer, Jan, "Historia Augusta: Nomen Antoninorum", en Acta Classica, 19 (1976), pp. 105-113.
} 
y cultural es un Imperio diverso en cuanto a lo religioso ${ }^{5}$. Esta diversidad se reflejaba en todos los estratos sociales. Si el común ciudadano tenía preferencias religiosas basadas en su origen y sus afinidades, los hombres y mujeres en lo más alto de la pirámide social también hacían gala de sus predilecciones. Entre las poderosas mujeres de la familia de los Severos tenemos varios ejemplos. Mientras que Julia Mamea mostró apego por los cristianos ${ }^{6}$, Julia Soemnia y Julia Mesa fueron fervientes creyentes de los cultos sirios. En la Hist. Aug. se ofrece una descripción del larario de Alejandro Severo, que en caso ser coincidente con la realidad, puede ser interpretada como un claro ejemplo de sincretismo ${ }^{7}$, aunque es cuestionable la veracidad que se puede otorgar a este pasaje como han señalado autores como Syme, por ejemplo ${ }^{8}$.

Además deleclecticismo, destaca el sincretismo como otro aspecto delos más característicos del sentir religioso del momento. En mayor o menor medida, muchos cultos provinciales habían sido aceptados o asimilados a otros tradicionalmente romanos. Las religiones mistéricas son un ejemplo de estas adopciones en complejo religioso. Los misterios de Magna Mater o de Eleusis eran plenamente reconocidos y encontraban gran aceptación. Los cultos de Júpiter Doliqueno y Júpiter Heliopolitano encontraron gran difusión en tiempos de los Severos 9 .

La posición frente al monoteísmo varió de unos emperadores a otros. Con respecto a Septimio Severo es complicado afirmar con rotundidad cuál fue su postura, aunque todo parece apuntar a que estuvo más próxima a la tolerancia que a la hostilidad. Algunos autores cristianos lo tacharon de promotor de persecuciones contra su comunidad, como Eusebio de Cesarea $^{10}$, aunque otros como Tertuliano nos dan testimonio de su buena disposición para con sus correligionarios ${ }^{11}$. Tenemos constancia de que se dieron algunas persecuciones, pero estas tuvieron carácter local y fueron esporádicas ${ }^{12}$. Los testimonios de los que disponemos nos llevan a pensar que en el tiempo de sus sucesores la situación fue similar.

\footnotetext{
${ }^{5}$ Aguado García, Paloma, Religión y política religiosa del emperador Caracalla, tesis doctoral, Universidad Complutense de Madrid, 1999, pp. 353-354.

${ }^{6}$ Santos Yanguas, Narciso, El cristianismo en el marco de la crisis del siglo III en el Imperio Romano, Oviedo, Universidad de Oviedo, 1996, p. 184.

${ }^{7}$ Hist. Aug. Alex. Sev., 29, 2-3: "las estatuillas de los emperadores divinizados, [...] y las de los seres de gran honorabilidad, entre los que se hallaban Apolonio, [...], Cristo, Abrahán, Orfeo y otros personajes parecidos a ellos, y las estatuas de sus antepasados".

${ }^{8}$ Vid. Syme, Ronald, "Toleration and bigotry", en Birley, Anthony R. (ed.), Roman Papers III, Oxford, Claredon Press, 1984, p. 905. "Hence allurement for the credulous, be they cleric or lay, such as, notoriously, the domestic chapel ofthe devout Severus Alexander. [...] Indeed, by content or by context, each and all ofthe items are suspect". También se cuestiona la autenticidad del pasaje en Rohrbacher, David, The Play of Allusion in the Historia Augusta, Madison, University of Wisconsin Press, 2016, p. 96. Para Turcan, se trata de una burla, en la que se enfatiza la condición oriental del emperador: "Les quolibets visaient apparemment les dévotions syncrétiques de Sévère Alexandre qui rassemblait dans son laraire Apollonius de Tyane, Abraham, le Christ et Orphée, un peu comme son cousin Héliogabale avait prétendu réunir toutes les dévotions autour d'Elagabal". Turcan, Robert, "Les dieux de l'Orient dans l'Histoire Auguste", en Journal des Savants, vol. 1, 1 (1993), p. 33.

${ }^{9}$ Aguado García, Paloma, Religión y política... op. cit., p. 156.

${ }^{10}$ Euseb., Hist. eccl, VI, 1, 1 .

${ }^{11}$ Tert., Ad Scap., IV, 5-6.

${ }^{12}$ Aguado García, Paloma, "Cristianismo bajo Septimio Severo y Caracalla", en Espacio Tiempo y Forma. Historia Antigua, 13 (2000), p. 257. DOI: http://dx.doi.org/10.5944/etfii.13.2000.4377. Hipólito de Roma refería que fueron los gobernadores provinciales y las masas enfurecidas los que fomentan estas persecuciones y no el poder de Roma. Hippol., Dan., I, 15-20.
} 
Apunta Aguado García que "la tolerancia de hecho que existía en este momento en el Imperio, instaurada desde Marco Aurelio, pasaba por la circunstancia de que los cristianos aceptaran las reglas de convivencia política, y que participaran de las celebraciones paganas sin rechazos ni perjuicios"13. Es esta una opinión compartida por varios estudiosos que hablan de distintos grados de tolerancia desde finales del siglo II $^{14}$. Gracias a este clima surgieron diversos apologetas, como el citado Tertuliano o Clemente de Alejandría, que presentaron sus argumentos ante los defensores del paganismo. Sabemos de la celebración de sínodos desde el tiempo de Alejandro Severo. Los obispos romanos se sucedían, el poder de la Iglesia crecía progresivamente en las ciudades — incluida Roma — y la religión cristina se fue difundiendo cada vez más ${ }^{15}$.

En este contexto en el que el sincretismo y la tolerancia hacia la diversidad eran la tónica, la introducción del baal de Emesa en Roma no parece un movimiento inapropiado per se. En la religión romana existía una antigua religión solar, que en este ambiente de asimilaciones y aceptación podría haber sido aprovechada — como posteriormente haría con mucha más habilidad Aureliano-, para promocionar un dios unificador que ayudase a canalizar las inquietudes espirituales de los habitantes del Imperio. Emergería este culto como un símbolo de identidad colectiva, pues no era complicado encontrar alguna forma de culto al sol entre las diversas religiones locales de las provinciae.

\section{Política religiosa imperial}

El horizonte que vislumbraba Heliogábalo tras alcanzar el poder no era demasiado halagüeño. Su prioridad no fue estabilizar la situación política, como cabría esperar, sino centrarse en sus deberes como sacerdote del culto de El Gabal, título que ya ostentaba en su Siria nata ${ }^{16}$. Sabemos que durante su estancia en Nicomedia en el invierno del 218 ya se entregaba con fruición a estos menesteres ${ }^{17}$. Una de las constantes de su gobierno fue su rol

\footnotetext{
${ }^{13}$ Aguado García, Paloma, "Cristianismo bajo..." op. cit., p. 259.

${ }^{14}$ Sordi habla de "tolerancia de hecho", mientras que el profesor González Salinero la define como una "amplia tolerancia". Cf. Sordi, Marta, Los cristianos y el Imperio Romano, Madrid, Encuentro, 1988, pp. 79-93; y González Salinero, Raúl, Las persecuciones contra los cristianos en el Imperio Romano. Una aproximación crítica, Madrid, Signifer, 2005, pp. 56-58.

${ }^{15}$ González Salinero, Raúl, Las persecuciones... op. cit., p. 56. "La Iglesia se dotará de una sólida estructura interna que, en el ámbito disciplinar, girará definitivamente en torno al episcopado monárquico".

${ }^{16} \mathrm{Hdn} ., \mathrm{V}, 3,4$. Encontramos testimonios numismáticos de Heliogábalo como sumo sacerdote del culto de Emesa a partir del 219, según la cronología propuesta por Thirion. Vid. Thirion, Marcel, Le monnayage d'Elagabal (218222), Bruselas, J. de Mey, 1968, p. 20.

${ }^{17} \mathrm{Hdn} ., \mathrm{V}, 5,3-4$. Las fuentes numismáticas nos informan, en cambio, de que fueron los dos últimos años de su reinado aquellos en los que más testimonio se dejó de su faceta como sacerdote de El Gabal. Cf. Manders, Erika, Coining images of power: patterns in the representation of Roman emperors on imperial coinage, AD 193-284, Leiden, Brill, 2012, p. 147. DOI: https://doi.org/10.1163/9789004224001.
} 
como "oficiante", papel que a menudo eclipsaba su labor como mandatario. Mientras fue emperador, estos desempeños como sacerdote supusieron una constante distorsión en sus relaciones institucionales que llevaron a que delegase habitualmente en su consilium los asuntos del Imperio.

Pasaron muchos meses hasta que el sirio arribara a Roma, más de un año ${ }^{18}$. Es una cuestión llamativa y probablemente esté relacionada con el hecho de que la piedra de Emesa acompañara a la comitiva imperial en su trayecto hasta la capital. Cuando llegó a la ciudad finalmente, la instauración del culto fue prioritaria ${ }^{19}$.

\subsection{Introducción del culto}

Heliogábalo promocionó decididamente la religión de El Gabal tan pronto alcanzó la capital $^{20}$. Es necesario mencionar que sí que hay pruebas arqueológicas de un culto a la deidad previas al emperador sirio ${ }^{21}$, pero fue Heliogábalo quien trasladó desde su tierra natal toda la estructura y la organización. Prueba de ello la encontramos en la decisión de llevar a Roma el betilo que adoraban los emesenos, construir un impresionante templo para albergarlo y honrarlo y, por si fuera poco, ubicar al dios por encima de cualquier otra divinidad del panteón. Para Dion Casio este fue su gran sacrilegio ${ }^{22}$.

Sabemos de la progresividad teológica de la religión romana desde sus orígenes ${ }^{23}$. La asimilación de deidades extranjeras históricamente se llevó a cabo con bastante naturalidad gracias al utilitarismo definitorio de la mentalidad romana ${ }^{24}$. Cabe pensar, por tanto, que la

\footnotetext{
${ }^{18}$ Desde el 16 de mayo de 218 (Cass. Dio, LXXIX, 31), hasta julio de 219. Icks propone esta datación calculando la fecha de llegada en base a la información que aporta Eutropio, quien nos dice que Heliogábalo gobernó en Roma durante dos años y ocho meses (Eutr., VIII, 22). Icks, Martijn, The crimes... op. cit., pp. 17-18. De acuerdo a una inscripción hallada en un altar de Hercules Magusanus, en cambio, la fecha de llegada a la ciudad se retrasa hasta septiembre de eses mismo año. CIL VI, 31162.

${ }^{19}$ Como muestra de la importancia de su culto para el nuevo emperador, cf. las siguientes inscripciones, en las antepone el título de sacerdos al de pontifex maximus. Cf. ILS, 473, 475, 2008, 9058.

${ }^{20} \mathrm{Si}$ bien existían una cierta continuidad en los cultos solares dentro del complejo religioso romano, la religión del baal de Emesa, nada tenía que ver ni a nivel formal ni a nivel teológico con las distintas variantes de culto al sol más tradicional y de raigambre indoeuropea.

${ }^{21}$ Testimonios como la inscripción de Aelio Amando del año 158 así lo evidencian. CIL VI, 715. Vid. Halsberghe, Gaston H., The Cult... op. cit., p. 45. Es posterior esta otra, datada en tiempos de Septimio Severo y Caracalla. CIL VI, 2269 Vid. Sánchez Sánchez, José Ignacio, La introducción... op. cit., p. 59. Sobre la génesis del culto a Sol previo a la llegada del emperador sirio existe un vivo debate. Autores como Von Domaszewski apoyan el origen autóctono del mismo, mientras que otros señalan un origen externo, bien griego, como Wissowa, bien semítico, como Hijmans. Cf. Von Domaszewski, Alfred, "Die politische Bedeutung der Religion von Emesa", en Von Domaszewski, Alfred, Abhandlungen zur Römischen Religion, Leipzig, Teubner, 1909; Wissowa, Georg, Religion und kultus der Römer, Munich, CH Beck, 1902; y Hijmans, Steven E., "The Sun which did not Rise in the East. The Cult of Sol Invictus in the Light of Non-Literary Evidence", en BABESCH. Annual Papers on Mediterranean Archaeology, 71 (1996), pp. 115-150.

${ }^{22}$ Cass. Dio, LXXX, 11. "To Dio, the cult of god Elagabalus was just another form of sexual perversion [...] Elagabalus'prime offence consisted, as far as religion is concerned, in his placing him (the god Elagabalus) even before Jupiter". Sommer, Michael, "The Challenge of Aniconism: Elagabalus and Roman Historiography", en Mediterraneo Antico. Economie, Societá, Culture, vol. 11, 1-2 (2008), p. 583.

${ }^{23}$ Bayet, Jean, La religión romana. Historia política y psicológica, Madrid, Ediciones Cristiandad, 1984, p. 17.

${ }^{24}$ Encontramos varios comentarios a este respecto en Beard, Mary et al., Religions of Rome. Vol. 1: A History. Cambridge, Cambridge University Press, 1998. Cf. A lo largo de los puntos 1.6, 2.1 o 4.2, por citar tres ejemplos, se trata esta cuestión. También en Salzman et al. (eds.), The Cambridge History of Religions in the Ancient World. Vol II. Cambridge, Cambridge University Press, 2013, se hace alusión a la gran capacidad para incorporar dioses,
} 
introducción del culto de $\mathrm{El} \mathrm{Gabal} \mathrm{no} \mathrm{tendría} \mathrm{por} \mathrm{qué} \mathrm{haber} \mathrm{supuesto} \mathrm{un} \mathrm{gran} \mathrm{problema} \mathrm{si} \mathrm{dicha}$ introducción hubiera sido llevada a cabo de un modo menos abrupto.

Nos consta la incorporación de dioses extranjeros al panteón romano a través de diversas vías. Así, el temor a una derrota frente a Aníbal, trajo a Cibeles desde Frigia en 204 a.n.e. ${ }^{25}$ En periodo republicano también fue cuando las tropas de Sila trajeron consigo a Mâ - luego Bellona tras la correspondiente interpretatio- desde Capadocia ${ }^{26}$. El ejército también sirvió para que el iranio Mithras alcanzara la Vrbs. Fueron en cambio comerciantes egipcios los que introdujeron a Isis y a Serapis procedentes de Egipto; mientras que los esclavos sirios de Sicilia abrieron las puertas de Italia a su diosa, Dea Syria ${ }^{27}$.

Algunas de estas modalidades de inclusión se sucedieron paulatina y espontáneamente, sin motivaciones dirigistas. Otras fueron orquestadas desde el poder, pero con una intencionalidad espiritual o estratégica, como para conjurar una amenaza, por ejemplo. Sabemos también de casos en los que el trasfondo político fue de mayor relevancia, como en los momentos en los que desde el trono, se mostró una preferencia más o menos evidente por una o varias divinidades, o por algún culto en concreto $^{28}$. Este fue el modo en que se promocionó el culto de El Gabal. A pesar de los esfuerzos del consejo por lubricar la inserción del dios y sus costumbres en Roma, las formas y las prescripciones de Heliogábalo no tuvieron en cuenta la sensibilidad de los sectores más conservadores de la sociedad y rompieron algunos de los más sagrados tabúes de la religión tradicional.

\subsection{Características: rituales, creencias y organización}

El Gabal era el dios principal de la ciudad de Emesa. Lenormant recoge hasta diez denominaciones distintas dadas por los autores clásicos para él ${ }^{29}$. Se le adoraba bajo la forma de una piedra negra procedente del cielo ${ }^{30}$. Este supuesto origen uránico la vinculaba directamente con la deidad. Sabemos de la frecuencia con la que en el ámbito religioso semita se dan este tipo de cultos. Autores como Clemente de Alejandría hacen referencia al hecho de que "los árabes adoran a las piedras" ${ }^{31}$.

rituales o cultos completos de la religión romana. De particular interés para este estudio, es el capítulo dedicado a Oriente Próximo, pp. 54 y ss.

${ }^{25}$ Liv., XXIX, 10-14.

${ }^{26}$ Lloyd-Morgan, Glenys, Nemesis and Bellona: a Preliminary Study of two Neglected Goddesses. The Concept of the Goddess, Londres, Routledge, 2002, pp. 124-126.

${ }^{27}$ Bayet, Jean, La religión... op. cit., p. 210.

${ }^{28}$ Habla Bayet de las querencias de Nerón por el mazdeísmo o el culto de Dea Syria, de la iniciación en los misterios eleusinos de Augusto, Adriano o Marco Aurelio, o de la devoción de Cómodo por Isis y Mitra; por ejemplo. Ibídem, p. 213.

${ }^{29}$ Lenormant, François, "Sol Elagabalus", en Revue de l'histoire des religions, 3 (1881), p. 310.

300bjetos como la piedra de Emesa o el betilo de Pesinunte, representación de la Kybele frigia, eran manifestaciones del dios. En palabras de Eliade, estos objetos — en este caso la piedra — "se singulariza y se le atribuyen cualidades sagradas". Eliade, Mircea, Tratado de Historia de las Religiones (morfología y dialéctica de lo sagrado), Madrid, Ediciones Cristiandad, 1974, pp. 253 y ss.

${ }^{31}$ Clem. Al., Protr., IV, 46, 2. 
Una deidad como El Gabal se revelaba como difusa en cuanto a su conceptualización para los romanos ${ }^{32}$. Desde hacía siglos y por influencia de los griegos, los dioses de Roma contaban con rasgos antropomorfos -incluso las abstracciones divinizadas como Pietas, Fortuna o Victoria, presentaban características humanas - de manera que tomar como dios preeminente a una piedra negra con extraños atributos tuvo que ser harto complicado para ellos.

Es lógico pensar que la piedra de Emesa arrastrara consigo a muchos de los miembros de su culto. Si bien Heliogábalo era el sumo sacerdote sabemos que había otros — sin ir más lejos, su primo Alexiano, el futuro Alejandro Severo - además del resto de individuos que pertenecían a la estructura de la organización. Los textos sugieren que algunas de estas personas fueron auténticos consejeros del emperador. Así, Zósimo apunta que "consagró su tiempo a magos y charlatanes" $" 33$ y el escritor de la Vita Heliogabali de la Hist. Aug. nos informa de que "magos de todas las clases le asistían y celebraban diariamente sacrificios"34. Entre los autores de nuestro tiempo también encontramos fuertes críticas al séquito del emperador y a los elementos que conformaban el culto ${ }^{35}$. Es incuestionable que debió haber muchos oportunistas y farsantes de todo tipo entre estos individuos, sin duda, pero obsérvense dos cuestiones. Sabemos que existía una gran sensibilidad por parte de los romanos hacia cualquier tipo de mago, adivino o predicador - a pesar de que los tolerasen y a menudo los consultasen - y el exotismo de las vestimentas y formas de los que acompañaban a Heliogábalo, pudieron causar especial impresión entre las voces que nos hablan de aquellos eventos. También se debe señalar que en torno a la aclamación de cualquier emperador, y máxime cuando esto sucede en las provincias, lejos de los ojos de la ciudad y del Senado, multitud de advenedizos surgen y se adhieren al nuevo régimen.

Sobre las características y la profesión del sacerdocio se deben hacer algunas precisiones. Nos consta que era hereditario. Julio Basiano, el padre de Julia Mesa ya era sumo sacerdote de El Gabal. Eran los varones de su familia quienes se encargaban de desempeñar el sacerdocio. El emperador era el hombre de mayor edad de aquellos que estaban facultados para heredar el cargo, por tanto él se encontraba en lo más alto de la jerarquía. A pesar de ya ser el más alto sacerdote del culto, hizo que el Senado incluyese en su titulatura imperial la denominación de Sacerdos Amplissimus Dei Invicti Solis Elegabali ${ }^{36}$, poniendo de relieve la importancia que siempre confirió a su religión, aún en detrimento de sus dignidades y obligaciones como emperador. De hecho, Halsberghe señala, apoyándose en la epigrafía que antepone este título al de pontifex maximus ${ }^{37}$, denominación típicamente romana. Encontramos en las monedas gran

\footnotetext{
${ }^{32}$ Equiparable en cuanto a lo abstracto al Yahvé hebreo.

${ }^{33}$ Zos., I, 11, 1.

${ }^{34}$ Hist. Aug. Heliog., 8,2.

${ }^{35}$ Halsberghe, Gaston H., The Cult... op. cit., p. 70.

${ }^{36}$ Frey, Martin, "Untersuchungen zur Religion und zur Religionspolitik des Kaisers Elagabal", en Historia Einzelschriften, 62 (1989), p. 80; CIL XVI, 139-141. Apoyándose en los hallazgos monetarios, Icks propone una fecha nunca anterior a los últimos meses del 220.

${ }^{37}$ Halsberghe, Gaston H., The Cult... op. cit., p. 71. Cf. nota 3.
} 
cantidad de referencias a estos títulos ${ }^{38}$. Más que un intento de acercar el culto a los romanos —y sabiendo del narcisismo del emperador y su obsesión por la religión del baal sirio— da la impresión de que a través de estos actos pretendía ante todo reivindicarse desde un punto de vista identitario.

Las fuentes literarias hacen referencia a un templo en territorio sirio extraordinariamente suntuoso $^{39}$. Tan pronto llegó a Roma, el emperador eligió otro como reflejo del de su tierra natal. Este santuario fue conocido como Elagabalium. Todo apunta a que estaba ubicado en el Palatino y al parecer fue una construcción bellísima ${ }^{40}$. En él se custodiaron tanto la piedra de Emesa como el resto de artefactos sagrados que por orden del emperador fueron trasladados. Fue también el lugar en el que se celebraron algunas de las exóticas ceremonias del culto ${ }^{41}$. La Hist. Aug. habla de la erección de un templo donde estuvo ubicado el de $\mathrm{Orco}^{42}$, que parece ser el mismo al que hace referencia Herodiano, aunque apenas sabemos nada de esta segunda construcción ${ }^{43}$.

Sabemos de algunos de los instrumentos litúrgicos que pudieron emplearse en el culto a través de la observación del numerario. Parasoles ${ }^{44}$ y abanicos ${ }^{45}$ son algunos de estos elementos que se representan con una cierta frecuencia en las acuñaciones en las que aparece la piedra sagrada. Más allá de estos accesorios, que podríamos definir como "funcionales" —aunque también cabe interpretarlos como objetos de status, de dignidad - entre la iconografía de las monedas de Emesa, encontramos otros relacionados con la ornamentación del dios. Delbrueck, en su estudio sobre las acuñaciones de Uranio de Emesa ofrece mucha información de interés a este respecto ${ }^{46}$. Habla el estudioso alemán de broches, tiaras y joyas entre los adornos que más se representan.

Sobre las ceremonias, la mayor parte de la información la encontramos en las fuentes literarias, aunque la numismática también nos informa de algunas cuestiones de gran interés. Entre otros datos, los textos clásicos refieren que los seguidores de El Gabal se abstenían de comer cerdo con el fin de purificarse. A Dion Casio esta privación le resultaba inaceptable, al igual que la circuncisión, que por lo que sabemos también era prescriptiva ${ }^{47}$. Se sugiere en este

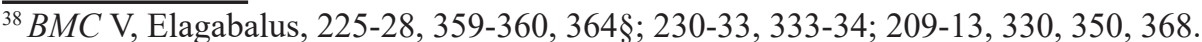

${ }^{39}$ Herodiano proporciona la descripción más completa en Hdn, V, 3, 4-6.

${ }^{40}$ Hist. Aug. Heliog., 3, 4; Cass. Dio., V, 5, 8. Cf. Chausson, François, "Vel Iovi vel Soli: quatre études autour de la Vigna Barberini (191-354)", en Mélanges de l'Ecole française de Rome. Antiquité, vol. 107, 2 (1995), pp. 661765; y de Arrizabalaga y Prado, Leonardo y Raúl de la Fuente Marcos, "The site of the Varian Temple of Elagabal in Rome: topographical and astronomical approach to the question", en Studies in language and literature. Language, 47 (2005), pp. 89-124.

${ }^{41}$ Cass. Dio., V, 5, 8 .

${ }^{42}$ Hist. Aug. Heliog., 1, 6-7. En la edición de Picón y Gascón, se anota que el templo de Orco es desconocido. Edición de Vicente Picón y Antonio Cascón, Madrid, Akal, 1989, p. 336, nota 4.

${ }^{43} \mathrm{Hdn}$., V, 6, 6. Se menciona que cada verano se celebraba un festival muy lujoso y popular, en el que se trasladaba al dios a este lugar.

${ }^{44}$ RIC 143 o RIC 196, por ejemplo.

${ }^{45}$ Delbrueck, Richard, "Uranius of Emesa", en The Numismatic Chronicle and Journal of the Royal Numismatic Society, vol. 8, 1-2, (1948), p. 18.

${ }^{46}$ Ibídem, p. 18

${ }^{47}$ Cass. Dio, LXXX, 11.
} 
mismo pasaje que el emperador además de cortar su prepucio e incitar a sus compañeros a hacer lo propio, planeaba castrarse, pero el senador griego concluye que este deseo tenía que ver más con su afeminación que con cualquier cuestión de carácter religioso. Se ha señalado que los seguidores del culto sí que llegaron a este extremo ${ }^{48}$. Se hace evidente la similitud con uno de los grandes cultos orientales de carácter mistérico que mayor influencia y aceptación alcanzó en Roma, el de Cibeles-Magna Mater.

Se ofrecen descripciones hiperbólicas de algunos aspectos del culto sirio. En Herodiano encontramos una de ellas en la que se detallan los sacrificios de multitud de animales y se habla de la utilización de plantas aromáticas y ricos vinos para las libaciones ${ }^{49}$. Se enfatiza lo relativo a las danzas y la música, así como la teatralidad de la escena, posiblemente con la intención de exagerar la "orientalidad" de las ceremonias. De gran relevancia también, es el hecho de involucrar sea como espectadores o participantes directos, a senadores, prefectos del pretorio y equites en estos rituales.

Uno de los aspectos más conflictivos en lo relativo a los ritos son los supuestos sacrificios humanos. La poco fiable Hist. Aug. afirma que tales sacrificios ocurrieron ${ }^{50}$. La clara intención del escritor es la de condicionar al lector. Se debe poner el foco en el interés por vincular las atrocidades descritas con el país natal del emperador, enfatizando su condición de bárbaro. Dion Casio también nos ofrece una truculenta descripción de estas ceremonias, en las que además de los asesinatos de niños encontramos el encierro de bestias en el templo del dios —un león, un mono y una serpiente concretamente $-{ }^{51}$ a los que se arrojaban genitales humanos, no se puede imaginar con qué propósito ${ }^{52}$. En el relato se alude también a encantos y amuletos, elementos mágicos, que causaban enormes reticencias a los romanos de mentalidad más tradicional, como es el caso del senador. Esté o no basada esta narración en hechos reales, la tendenciosidad del autor es más que evidente.

Otro aspecto ampliamente tratado por las fuentes es el del atuendo tanto del emperador como de los demás oficiantes en estas celebraciones. En la Historia Romana se hace mención al hecho de que Heliogábalo gustaba de vestirse con los atuendos orientales, hasta el punto de ser conocido como "El Asirio" 53 .

Para finalizar esta breve aproximación se debe llamar la atención sobre el festival que se celebraba en verano en honor a $\mathrm{El} \mathrm{Gabal,} \mathrm{en} \mathrm{el} \mathrm{que} \mathrm{la} \mathrm{imagen} \mathrm{se} \mathrm{trasladaba} \mathrm{desde} \mathrm{el} \mathrm{Elagabalium}$ en Roma al otro templo que hubo de haber en las afueras de la ciudad. Herodiano detalla el

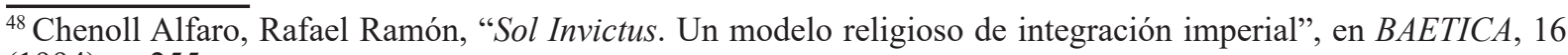
(1994), p. 255.

${ }^{49}$ Hdn., V, 8, 8-10.

${ }^{50}$ Hist. Aug. Heliog., 8, 1-2. Este punto es discutido en Gross, Karl, "Elagabal”, en Reallexicon für Antike und Christentum, 4 (1959), p. 994.

${ }^{51}$ Cabría pensar, en caso de que estos hechos ocurrieran, qué parte se correspondía con la mera teatralidad de la que Heliogábalo, por lo que se nos informa, era gran promotor y cuál tendría que ver con la vertiente religiosa.

${ }_{52}$ Cass. Dio, LXXX, 11.

${ }^{53}$ Cass. Dio, LXXX, 11. Otra mención a su indumentaria esta vez sin establecerse una relación directa con su condición de sacerdote la encontramos en Hist. Aug. Heliog., 23.
} 
evento señalando al solsticio estival como momento de su celebración ${ }^{54}$. Parece ser que fue muy popular entre el pueblo debido a las generosas distribuciones de alimentos. Durante este festival se ubicaba a la piedra sagrada sobre un carro adornado con oro y joyas, tirado por caballos blancos. Nadie conducía el vehículo sino el propio dios. El emperador caminaba de espaldas mirando hacia el betilo por delante de la comitiva. Finalmente se lanzaban regalos a las masas que se agolpaban en torno al templo. Las fuentes numismáticas han permitido también reconstruir en parte esta celebración.

\subsection{Las transgresiones del emperador}

Ya hemos visto que son varios los aspectos que pueden considerarse conflictivos en lo tocante a la inserción del culto. Desde el consejo del emperador esta cuestión no se pasó por alto. Se intentó, colocando un retrato de Heliogábalo ataviado como sacerdos en el Senado, atenuar el shock cultural, familiarizar a los romanos con su nuevo emperador-sacerdote y también observar el comportamiento de los miembros de la institución ${ }^{55}$. Es cierto que se consiguió que el pueblo no se extrañase al ver en persona a su nuevo gobernante vestido con tan extravagante atuendo y ofreciendo un sacrificio a un dios foráneo. En cambio, la clase senatorial, no reaccionó favorablemente.

Son dos los elementos que mayoritariamente jugaron en contra del emperador y atentaron contra los valores y las expectativas de la sociedad romana. Por una parte tenemos su condición sexual y el comportamiento derivado de la misma, pero no es esta cuestión el objeto de la presente investigación ${ }^{56}$. También, el factor cultural fue determinante. Heliogábalo, en tanto que fervoroso sacerdos sirio, tuvo que tener una serie de creencias y una configuración ideológica muy distinta a la que se esperaría de un emperador romano en el sentido tradicional. Encontramos ejemplos en diversos episodios de su biografía. Si él pretendía honrar a prefectos del pretorio y otras personalidades invitándoles a participar de una forma activa en los rituales en honor de su dios, los agasajados probablemente no encontrasen grato formar parte de aquellas exóticas ceremonias. Igualmente, puede que su percepción del casamiento con la vestal Severa, no fuera la de estar violando un terrible tabú, sino la de celebrar una santa unión hierogámica, ritual con fuerte enrizamiento en el sustrato religioso oriental ${ }^{57}$. Del mismo modo, las extrañas teogamias que promovió entre $\mathrm{El} \mathrm{Gabal} \mathrm{y} \mathrm{diversas} \mathrm{diosas,} \mathrm{encontrarían} \mathrm{su} \mathrm{origen} \mathrm{en} \mathrm{la} \mathrm{antigua} \mathrm{tradición}$ religiosa que le fue legada, pero resultaron extrañas al común de los romanos. Qué duda cabe que al margen de estos hechos, la promoción del baal sirio por encima del mismo Júpiter, a

\footnotetext{
$\overline{{ }^{54} \mathrm{Hdn} ., \mathrm{V}, 6,6-10 .}$

${ }^{55} \mathrm{Hdn} ., \mathrm{V}, 6-7$.

${ }^{56}$ Además de los trabajos mencionados en la nota 3,cf. Urías Martínez, Rafael, "Transgresión sexual y transgresión religiosa en Heliogábalo", en Alvar Ezquerra, Jaime et al. (eds.), Sexo, muerte y religión ... op. cit., pp. 205-213.

${ }^{57}$ Frazer nos habla de estas prácticas en diversos lugares, como Grecia, Egipto o Mesopotamia. Frazer, James George, La rama dorada, México, Fondo de Cultura Económica, 1944, pp. 178 y ss.
} 
pesar de poder llegar a imaginarse empatizando con la mentalidad despótica de un monarca oriental y en el ambiente de sincretismo religioso que imperaba en el siglo III en el Imperio, no puede interpretarse de otra manera que como una gravísima afrenta. La juventud del emperador y su carácter narcisista son otros dos factores que han de tenerse muy en cuenta a la hora de explicar su comportamiento y sus decisiones.

Confrontando las fuentes de las que se disponen, se puede concluir que estas fueron las principales transgresiones de Heliogábalo:

- Se ubicó su retrato sobre la imagen de Victoria en el edificio del Senado ${ }^{58}$.

— Elevó a El Gabal a lo más alto del panteón ${ }^{59}$.

- Practicó ayunos purificadores y prescribió la circuncisión ${ }^{60}$.

- Tras violar el templo de Vesta, casó con una de sus vírgenes, Julia Aquilina Severa ${ }^{61}$.

- Se llevó de sus lugares de origen a los objetos sagrados ${ }^{62}$.

- Casó a El Gabal con otras diosas ${ }^{63}$.

- Obligó a los próceres de la ciudad a participar en las ceremonias de su culto ${ }^{64}$.

\section{3. ¿Crisis generalizada? Las reacciones}

\subsection{El Senado}

Tras imponerse sus tropas a las de Macrino en Antioquía, el joven emperador envió una carta al Senado declarándose nieto de Severo, hijo de Caracalla, César y Augusto, además de depositario del poder tribunicio y de otros títulos ${ }^{65}$. Los senadores, que se habían visto obligados a aceptar al malogrado Macrino, de nuevo, se vieron atrapados en una confusa maraña de fidelidades y no les quedó más alternativa que aceptar al nuevo emperador de facto. Rápidamente, al igual que ocurrió con el ejército, el Senado comprendió que tal vez no hubiera sido una buena idea respaldar al sirio.

Tras tardar más de un año en personarse en Roma, en cuanto llegó se entregó al sacerdocio de El Gabal y a sus deleites personales, en lugar de tomar las riendas del Imperio. Estas cuestiones 
pasaron de ser un potencial inconveniente a un auténtico problema cuando Heliogábalo mostró clara preferencia por el ejercicio de su sacerdocio frente a sus responsabilidades como gobernante. En la Hist. Aug. se afirma que, tan pronto llegó a Roma, se desentendió por completo de la administración de las provincias y empleó todas sus energías en promocionar el culto de su $\operatorname{dios}^{66}$. Aunque ya se ha mencionado anteriormente que de acuerdo con las evidencias numismáticas el apogeo de la actividad sacerdotal podría fecharse a partir del año 220, un antoniniano fechado un año antes en Roma ${ }^{67}$ nos muestra al emperador ofreciendo un sacrificio ante su deidad, sobre un carro. Baldus propone que esta representación del emperador como sacerdos podría seguir el mismo modelo de la imagen que se llevó al Senado ${ }^{68}$. Es complicado establecer si esto fue así, pues, como sabemos, existen diversas tipologías en el numerario de Heliogábalo en las que aparece como oferente, pero en cualquier caso, puede afirmarse, que el emperador desde que llegó a la $\mathrm{Vrbs}$, no tuvo el mayor inconveniente en mostrar a su dios y ejercer su sacerdocio en público ${ }^{69}$.

Los senadores se hubieron de entender principalmente con su consejo ${ }^{70}$, en especial con las mujeres de su familia, que según algunas fuentes tuvieron que ser aceptadas en la institución ${ }^{71}$, hecho que debió ser tomado como un insulto para sus integrantes en caso de que realmente ocurriera. Por otra parte, en el Senado heredado - a pesar de contar con un porcentaje considerable de miembros africanos y orientales $-{ }^{72}$ existía un poso de conservadurismo que seguramente no contemplase con buenos ojos un imperator con unas formas y un aspecto tan "bárbaro". Sobre el ya mencionado envío a Roma del retrato del emperador se puede concluir que si tal vez pudo ser una buena idea anticiparse y presentarlo con su indumentaria y en el ejercicio de sus obligaciones sacerdotales que tan importantes parecían ser para él, la ubicación que se eligió para el retrato no fue nada afortunada y pone de manifiesto un gran desconocimiento del protocolo y las tradiciones. La prescripción a la que se hace alusión tampoco se queda a la zaga: "Ordenó a todos los magistrados romanos y a todos los que ejecutaban sacrificios públicos que dieran la precedencia al nombre del nuevo dios Elagábalo, delante de los demás dioses a quienes invocaban los oficiantes de los sacrificios"73. De ser cierto lo que refiere Herodiano, los senadores en particular, y los ciudadanos en general, hubieron de encontrar ofensiva la obligación de ofrecer sacrifico con carácter prioritario a El Gabal, un dios extranjero, cuya imagen y la de su sumo sacerdote, se había colocado por encima, nada menos de la imagen de Victoria que presidía el honorable edificio senatorial.

\footnotetext{
${ }^{66}$ Ibídem, 3, 4.

${ }^{67}$ La pieza no se encuentra en el RIC. Kunsthistoriches Museum Wien, Bundesslg. von Münzen, no 43082.

${ }^{68}$ Baldus, Hans Roland, "Das «Vorstellungsgemälde» des Heliogabal: ein bislang unbekanntes numismatisches Zeugnis", en Chiron, 19 (1989), pp. 471-476.

${ }^{69}$ Vid. Martin, Jean-Pierre, "Sol Invictus: des Sévères à la tetrarchie d'après les monnaies", en Cahiers du Centre Gustave Glotz, 11 (2000), pp. 300 y ss.

${ }^{70}$ Hdn., V, 5, 1 .

${ }^{71}$ Hist. Aug. Heliog., 4.

${ }^{72}$ Le Glay, Marcel, Grandeza y caída del Imperio Romano, Madrid, Cátedra, 2002, pp. 246-247.

${ }^{73} \mathrm{Hdn} ., \mathrm{V}, 7$.
} 
Se aprecia en la biografía del emperador un cierto movimiento pendular especialmente en las primeras fases de su mandato entre sus pulsiones, querencias y costumbres; y lo que cabría esperar de un emperador de Roma. Sin duda su consilium tuvo mucho que ver con esto tratando de mitigar sus medidas más extremas y proponiendo políticas de moderación y gestos que le congraciasen con pueblo y Senado. Entre estas medidas se ha de encuadrar la boda con Julia Cornelia Paula — miembro de una de las más poderosas familias de la ciudad — ${ }^{74}$ que sin duda fue una maniobra para tratar de agradar a los notables ${ }^{75}$. Sabemos que no duró mucho esta unión y en un movimiento opuesto, Heliogábalo decidió dejarla y tomar como esposa a Julia Aquilina Severa, una virgen vestal. Se nos dice que tras violar el templo de Vesta se casó el emperador con la sacerdotisa ${ }^{76}$, con la descabellada voluntad de corroborar su virilidad ${ }^{77}$. Es difícil imaginar una afrenta más grande en el ámbito del formalismo religioso romano. La institución de las Vírgenes Vestales fue una de las más antiguas de Roma. La tradición atribuye su instauración a Numa Pompilio ${ }^{78}$ y de estas mujeres sin mácula dependía, nada menos, la seguridad de la ciudad. Su virginidad, literalmente, era una cuestión de estado. Las niñas cuando accedían al sacerdocio pasaban a ser hijas de Roma. Cualquier relación sexual con otro romano sería equivalente al incestum ${ }^{79}$, además de un acto de traición ${ }^{80}$. No es difícil imaginar, por tanto, cuál sería la reacción de la sociedad ante el matrimonio entre el emperador y la vestal. Tuvo que ser interpretado como un ultraje a la esencia misma de la romanitas. Heliogábalo, en cambio, no debió de percibirlo en absoluto como un acto transgresivo. Creyéndose él divino y casándose con la sacrosanta persona de Julia Aquilina Severa consideraba su matrimonio como una unión sagrada ${ }^{81}$.

\footnotetext{
${ }_{74}^{74}$ Ibidem, V, 6, 1 .

${ }^{75}$ Parece que Mesa fue su principal influencia en esta etapa. Medidas como la supuesta carta escrita al Senado disculpándose por la unión con la vestal o su representación en numismas capite velato, al modo del Pontifex Maximus tradicional, son dos de ellas.

${ }^{76}$ Ibídem, V, 6, 2. En este mismo pasaje se menciona una carta al senado en la que "se disculpaba su crimen e impiedad diciendo que había sido víctima de una pasión humana; que había sido vencido por el amor de una doncella y que el matrimonio de un sacerdote y una sacerdotisa era justo y santo". Nótese la relación entre esta unión y las de El Gabal con las diosas.

${ }^{77}$ Ibídem. El hecho de que se haga referencia a la virilidad sugiere que era este un tema que estaba en tela de juicio. $\mathrm{Si}$ creemos lo que se refiere en las fuentes, especialmente en la nunca confiable Hist. Aug., sus actividades sexuales y sus actitudes, debieron de ser harto escandalosas. Un ejemplo paradigmático lo encontramos en 5, 2-3: "¿quién podía soportar a un emperador que absorbía placer por todas las cavidades de su cuerpo, cuando nadie toleraría un comportamiento similar ni siquiera en una bestia? En fin, se limitaba en Roma, como única actividad, a procurarse emisarios que le buscaran individuos con buenos cojones y se los llevaran a su mansión, a fin de poder disfrutar de sus cualidades".

${ }^{78}$ Son tres los autores que nos informan a este respecto, Tito Livio (Ab Urbe Condita, I, 20), Plutarco (9.5-10) y Aulo Gelio. Para un estudio en profundidad, $c f$. Staples, Ariadne, From Good Goddess to Vestal Virgins: Sex and Category in Roman Religion, Londres, Routledge, 1998.

${ }^{79}$ Así se refieren en la Hist. Aug. a la relación del emperador con la sacerdotisa. Hist. Aug. Heliog., 6, 6.

${ }^{80}$ El castigo para la vestal por romper su voto, consistía en ser encerrada en un cubículo con algo de comida y agua hasta su muerte en el Campus Sceleratus. De este modo, se salvaban dos prohibiciones rituales, la de derramar su sangre y la de enterrarla viva dentro de los límites de la ciudad, pues al aprovisionar y conceder algo de espacio a la condenada, se podía considerar que técnicamente no se la estaba enterrando y morían incruentamente.

${ }^{81}$ Según Dion Casio, pretendía engendrar "niños parecidos a dioses". Cass. Dio, LXXX, 9, 3. Se ha de hacer referencia a la otra unión matrimonial que nos consta, con Ania Aurelia Faustina, a la que presenta como Iuno Caelestis.
} 
Al igual que ocurrió con el ejército, los senadores tuvieron que sentir un profundo rechazo cuando Heliogábalo promocionó a los personajes que le rodeaban ${ }^{82}$, muchos de ellos vinculados al culto de El Gabal probablemente — sea por devoción auténtica u oportunismo- pero sin preparación para desempeñar las funciones correspondientes a tales cargos.

\subsection{El ejército}

El ejército fue el eje de la revuelta que puso fin a Macrino y abrió las puertas a Heliogábalo. Descontento el estamento militar con un emperador que había pactado la paz con los partos, alzó a otro que supuestamente era hijo de Caracalla, un gobernante que, al menos en determinados sectores del estamento militar era recordado con nostalgia. Les pareció agradable el futuro emperador cuando aún en Emesa oficiaba como sacerdote ${ }^{83}$. La belleza y la entrega del muchacho complacían a las tropas acantonadas en Siria. Pero no tardó en tornarse este agrado en inquietud y vergüenza ante su comportamiento ${ }^{84}$.

Los cultos solares estaban sumamente extendidos entre los soldados. Nos consta que los legionarios de la Legio III Gallica saludaban al sol al estilo sirio ${ }^{85}$. Por tanto, seguramente fueran muchos los legionarios de los que elevaron al muchacho hasta la púrpura seguidores del culto de $\mathrm{El} \mathrm{Gabal}^{86}$, pero las costumbres y los gustos del nuevo emperador, cada vez más, fueron un auténtico obstáculo en su relación con él. Tanto la indumentaria como los bailes, así como el maquillaje propio de mujeres con el que se adornaba Heliogábalo molestaba profundamente a los soldados. A pesar de que muchas de estas cuestiones tenían que ver con el ejercicio del sacerdocio, otras se vinculaban a la condición sexual del sirio. Según nos dan a entender los autores clásicos, eran estos actos y comportamientos los que más escandalizaban al ejército ${ }^{87}$.

No parece opcional o voluntaria la participación de los cuerpos de élite del Imperio en las celebraciones del culto, como en la procesión que describe con gran detalle Herodiano, en la que relata cómo guardaespaldas, caballeros y la Guardia Pretoriana al completo, acompañaban a la piedra de Emesa y al emperador ${ }^{88}$. Cabe pensar que, al igual que ocurría con los senadores a los que también involucró en sus celebraciones, entre los militares que no habían sido promocionados por él o aquellos que sencillamente no le eran afectos ${ }^{89}$, pudiera ir consolidándose una opinión cada vez más desfavorable.

\footnotetext{
${ }_{82} \mathrm{Hdn} ., \mathrm{V}, 7,8$.

${ }^{83}$ Ibídem, V, 3, 8-9

${ }^{84}$ Hist. Aug. Heliog., 5, 1.

${ }^{85}$ Tac., Hist., III, 24.

${ }^{86}$ Herodiano menciona la costumbre de los soldados acampados en las inmediaciones de Emesa de ir al templo a celebrar el culto. También apunta que muchos de ellos eran clientes de Mesa, hecho que viene a reforzar la hipótesis anteriormente propuesta.

${ }^{87}$ Hdn., V, 7, 1.

${ }^{88}$ Ibídem, V, 6, 8

${ }^{89}$ Entre los que le apoyaron desde el principio, tenemos constancia de la recompensa que varios de ellos recibieron. Comazón, fue prefecto del pretorio, compartió el consulado con el emperador en 220 y además fue tribuno de
} 
En última instancia da la impresión de que, al menos para el ejército, las conductas sexuales del emperador fueron el detonante de que su núcleo duro, la Guardia Pretoriana, acabara con su vida y su mandato ${ }^{90}$.

\subsection{El pueblo llano}

Llama la atención Herodiano sobre el hecho de que, a pesar de llegar ataviado con la indumentaria propia de un sacerdote extranjero, gracias a la imagen que se había hecho traer previamente, "los romanos [...], no se asombraron" ". No da la impresión de que las masas se vieran particularmente afectadas por las reformas religiosas del sirio. Las exóticas ceremonias o el casamiento con la vestal tuvieron que resultar actos extraños e inquietantes, pero las fuentes no dan a entender que se articulara una respuesta de repulsa generalizada o un frente de oposición entre las clases no privilegiadas. De hecho, si apuntan los textos en algún sentido es al contrario. Así, sabemos que el festival anual en honor a El Gabal llegó a ser muy popular pues se celebraban juegos de gran lujo y atractivo, y además se repartían suntuosos objetos y animales domésticos entre los asistentes ${ }^{92}$. La supuesta generosidad de Heliogábalo también queda atestiguada en la ceremonia de su acceso al consulado ${ }^{93}$. En cualquier caso, tengamos en cuenta que los relatos de que disponemos son a menudo parcialistas y exagerados, por lo que deberíamos ser cautelosos al respecto ${ }^{94}$.

\subsection{Otros agraviados}

Como se ha visto, en los rituales del culto a El Gabal también se involucraba a caballeros, prefectos del pretorio y otros cargos. Del mismo modo que los senadores, y a pesar de querer el emperador honrarles, puede que tales honores no les resultaran agradables al ser habitualmente tarea de esclavos.

No es complicado tampoco imaginarse, por ejemplo, la estupefacción de los sacerdotes cartagineses de la Urania de la que nos habla Herodiano, al ver que su diosa es trasladada a Roma para ser casada con un betilo ${ }^{95}$, previo pago de una dote. Los custodios del Paladión o los

Roma hasta tres veces. Provenía de una familia de actores y sin duda su promoción, tuvo que ser mal vista por otros militares y políticos.

${ }^{90}$ Rantala, Jussi, "Call me not Lord for I am a Lady - Emperor Elagabalus and the Problem of Gender in the History of Cassius Dio", en Language and Scientific Imagination. The 11th International Conference of ISSEI, Helsinki, 2010. Se señala en este trabajo, que además de la conducta sexual del emperador, sus medidas religiosas molestaron considerablemente al ejército. $C f$. p. 3 .

${ }^{91}$ Hdn., 5, 5, 7-8.

${ }_{92}^{2}$ Hdn., V, 6, 6-9.

${ }^{93}$ Hist. Aug. Heliog., 8, 3.

${ }^{94}$ Herodiano, si bien nos habla en varias ocasiones de los obsequios del emperador para su pueblo, también deja de manifiesto que eran estos auténticos actos de despilfarro y que en las distribuciones morían muchas personas en los tumultos que se ocasionaban. $C f$. Hdn., V, 6, 10: "la fiesta de aquel dios causaba la desgracia de mucha gente". ${ }^{95}$ Ibídem, V, 6, 3-5. En este pasaje, se nos informa de que se casó al dios sirio con Palas Atenea primero, pero como "el dios sentía desagrado por una diosa siempre en armas y amiga de la guerra", se promovió otra unión, esta vez 
Salii, sin duda, se alarmarían al ver cómo sus objetos sagrados eran extraídos de sus templos para ser enviados al Elagabalium. Los cristianos, samaritanos y judíos, de ser cierto lo que se menciona en la Hist. Aug., tampoco tuvieron que reaccionar muy positivamente ante las supuestas intenciones de integrar los secretos de estos cultos en el de El Gabal $^{96}$.

\subsection{Las consecuencias}

Las actitudes de Heliogábalo y su comportamiento fuera de control precipitaron su final. Parece ser que el origen del fin de Heliogábalo, al igual que su ascenso, guarda estrecha relación con las maniobras de su abuela. Muy consciente del descontento que reinaba entre senadores y sobre todo, en el seno del ejército, hubo de preparar la salida del mayor de sus nietos y la aclamación del menor de ellos, Alejandro ${ }^{97}$. Fue muerto por su Guardia Pretoriana y profanado su cadáver primero por los soldados y después por una turba enfurecida ${ }^{98}$. Altheim habla de una "reacción nacional" y llama la atención sobre la imbricación existente ente religión y Estado para Roma: un emperador que no respeta a los dioses de la ciudad no merece ostentar el poder ${ }^{99}$.

Ascendió después Alejandro Severo, quien había sido debidamente educado dentro de los cánones más convencionales ${ }^{100}$. En el contexto del programa definido para limpiar el nombre de la dinastía tras los excesos de Heliogábalo, el culto a El Gabal fue desterrado de Roma ${ }^{101}$ y se restituyeron todos los objetos sagrados que se habían trasladado al Elagabalium ${ }^{102}$. La piedra fue devuelta a Emesa donde el culto recuperó su carácter local. Las evidencias numismáticas, ponen de relieve que se restituyó la religión y El Gabal continuó a la cabeza del panteón de la ciudad siria ${ }^{103}$.

\section{Conclusiones}

Tomando en consideración todo lo anteriormente expuesto se puede concluir que en términos generales, la política religiosa de Heliogábalo supuso un impacto considerable para la

con "Urania, diosa muy venerada por los cartagineses y los pueblos de Libia, [...] los fenicios la conocen con el nombre de Astroarque y pretenden que es la diosa de la luna. Antonino manifestó que resultaba muy adecuado el matrimonio del sol y de la luna y envió a buscar la estatua con todo el oro que en el templo había." Cf. Cass. Dio, LXXX, 12, 1.

${ }^{96}$ Hist. Aug. Heliog., 3, 5.

${ }^{97}$ Hdn., V, 7 y 8.

${ }^{98}$ Hist. Aug. Heliog., 16, 5; 17; 33, 7; Hdn., V, 8, 8-10.

${ }^{99}$ Altheim, Franz, A history of Roman religion, Londres, Methuen, 1938, p. 458.

${ }^{100} \mathrm{Hdn} ., \mathrm{V}, 7,5$.

${ }^{101}$ Cass. Dio, LXXX, 21, 2. La damnantio memoriae promulgada por el Senado, dada la vinculación existente entre el emperador y su dios, se hizo extensiva también a la deidad, como lo atestiguan algunas inscripciones. $C f$. $A E$ 2001, 2165; $A E$ 2001, 938; $A E$ 1997, 160; o $A E$ 1985, 976.

${ }^{102}$ Hdn., VI, 1, 3.

${ }^{103}$ Cf. Delbrueck, Richard, "Uranius of...” op. cit., pp. 11-29. 
sociedad romana. El clima era tenso tras el advenimiento y caída de Macrino y se esperaba la llegada del nuevo emperador. Pero quien arribó a Roma fue un joven sin ninguna experiencia, en cuya persona convergían las facetas de un sacerdote fanático de un culto extranjero y de un hedonista caprichoso y desenfrenado.

Tras la restauración de los Severii, la política religiosa emprendida por el emperador distó mucho de calmar las aguas y la llegada del dios sirio no tuvo muy buena acogida entre algunos de los sectores más influyentes de la sociedad. Como conclusión general se puede afirmar que la introducción del culto de $\mathrm{El} \mathrm{Gabal} \mathrm{en} \mathrm{Roma} \mathrm{contribuyó} \mathrm{a} \mathrm{acrecentar} \mathrm{la} \mathrm{inestabilidad} \mathrm{tanto} \mathrm{en}$ la Vrbs como en el resto del Imperio. Fijándonos ahora en los distintos estratos sociales deben hacerse las siguientes precisiones:

- La aceptación del culto por parte de los senadores y la élite romana, no fue más que superficial. Aunque desde el consilium del emperador se intentó evitar el conflicto con los notables, se ha comprobado que la institución se sintió ultrajada en varias ocasiones con las medidas religiosas que se tomaron. Fue la elevación de El Gabal a lo más alto del panteón la más controvertida de ellas. La clase senatorial fue la más agraviada.

— Las innovaciones en materia religiosa de Heliogábalo afectaron también al ejército. Su opinión en principio favorable sobre el nuevo gobernante cambió rápidamente y las cuestiones relativas al culto, aunque no se puede afirmar que fueron las de más peso, se sumaron a otras y favorecieron que se sucediera el desenlace que conocemos. El estamento militar fue afectado, aunque no en la misma medida que lo fue el Senado.

— Las magistraturas y las diversas jerarquías religiosas se pudieron ver desestabilizadas o afectadas puntualmente, aunque estos episodios no se concretaron en reacciones reseñables, sino más bien contribuyeron a enrarecer el ambiente general.

- La práctica carencia de referencias a la reacción popular frente a la cuestión de $E l$ Gabal, no nos permite hacer una valoración en profundidad del sentir del pueblo llano. En cualquier caso, si analizamos los pocos datos de los que disponemos, el giro religioso promovido por el emperador no tuvo que causar demasiado impacto entre las masas.

La inserción del culto fue un elemento de inestabilidad considerable, pero no puede afirmarse que motivase una crisis generalizada en la sociedad romana. Los conflictos y desequilibrios motivados por el movimiento hacia el henoteísmo promovido por Heliogábalo parece que afectaron más a la esfera política que a la social. 